\title{
The Origin of the Social Transformation of Care
}

\section{Verónica Maza D*}

Department of Law, The Autonomous City of Buenos Aires, Argentina

*Corresponding author: Daniela Verónica Maza, Lawyer graduated from the Universidad Nacional del Litoral (UNL), Coadjuvant Public Defender of the Defense Office before the Federal Courts of the City of Buenos Aires, PhD candidate in Legal Sciences (UMSA),

Investigation Paper

Volume 4 Issue 1

Received Date: February 23, 2021

Published Date: March 15, 2021

DOI: $10.23880 /$ abca-16000166 Postgraduate in Gender and Law (UBA), Specialized in Law (USal), Technician in Gender Equality (EUROINNOVA) and Diploma in Management of Organizations with a Gender Perspective (UAI). Teacher at various universities, researcher and speaker in various specialized academic spaces addressing the issue of care, health, disability and gender, Argentina, Email: danielamaza89@gmail.com

\section{Abstract}

The present work explores the factors that led to the change in social behavior to provide care. The results obtained in a qualitative investigation carried out in the City of Buenos Aires on the familiarization and judicialization of the care of people with disabilities is shown. Deepening the origin of the transformation of care based on the factors (objective and subjective) that promoted the change contributes to the identification of the causes that generated the self-care deficit presented by the people who care.

Keywords: Gender; Care; Judicialization; Familiarization

\section{The Origin}

Care ensures the protection and rights of populations. Analyzed from the demographic dimension, research carried out in the field of other disciplines warned about the entity of the care problem and determined that the demands for support to care increased. Among the great transformations that took place in the first half of the 20th century in Latin America, the accelerated decline in mortality in the last three decades stands out, but what was transcendental was the reduction in fertility that was accompanied by an economiccultural revolution and the massive incorporation of women into the labor market. In turn, mortality in several countries has reached low levels with the expectation of few marginal changes, although, as ECLAC points out, "there are significant gaps in the levels of morbidity and mortality, which are indicators, among other factors, of the adverse economic conditions in which part of the population lives and the lack of equitable access to health care".

From the economic point of view, care is developed in unfavorable scenarios both locally and regionally. Thus, the economies of South America decreased on average by $0.7 \%$ in the first quarter of 2019. Five economies contracted in the first quarter (Argentina, Nicaragua, Paraguay, Uruguay and Venezuela), and Brazil slowed down $(0.46 \%)$ the rest did not generate high growth rates. Regarding the labor market, during the first quarter of 2019 the indicators show a deterioration in the average quality of employment, and the largest source of new jobs was the informal sector, which has usually been characterized by low and unstable labor income and protective conditions precarious labor and social conditions (ECLAC) [1], all of which deepened with the crisis caused by the COVID-19 pandemic, whose social isolation halted activity, highly deteriorating the world economy. These imbalances in the economy, the increase in life expectancy at birth, and the reduced population growth have impacted on the way in which care is provided, differentially impacting those people who, due to their age, disability or pathology, require greater care.

Analyzing this phenomenon from the perspective of families, it was observed that they organize care by establishing a sexual division of this work, distributing it 
unequally between men and women. This organizational dynamic, an expression of gender relations in the world of work, shows subordinate relations of women [2], whose manifestation is their concentration on care responsibilities and their lesser and worse participation in the labor market, and that, despite the progress of some countries in Latin America and the Caribbean, in the Time Use Surveys (hereinafter EUT) it is evidenced that a rigid sexual division of labor based on unequal power relations [3], which prevents women from reducing the burden of this work. In the Montevideo Strategy for the implementation of the 2030 agenda, it was stated that inequality in relation to gender was verified by verifying that the increasing participation of women in the labor market is not accompanied by a greater participation of men in work unpaid domestic and care.

In the same way, it was indicated that when care work is inserted in the market, it is carried out mainly by women in three sectors of the economy: paid domestic work, health and education, with an unjust and unbalanced social organization subsisting, with strong implications in terms of inequality gaps between genders, and between women of different socioeconomic levels, territories and countries.

It was highlighted that many Latin American and Caribbean women are part of global care chains that, in the absence of men's participation, are constituted through the transfer of care work from one woman to another, on the basis of power relations according to sex, class and place of origin, and that in the coming decades the aging process of the region's population will worsen and, therefore, the burden of caring for the elderly, the chronically ill will increase and people with disabilities, increasing the costs of health care and pension systems.

The authorities participating in the strategy expect a decrease in fertility by 2030 , which will continue to be stratified according to socioeconomic level and racial and ethnic origin. In other words, the States warn that these elements favor the deficit of economic autonomy of women if they are not faced with urgent public policies that respond to the demands of care for people with some level of dependency and that explicitly consider the rights of women. caregivers, whether paid or not, so that their possibilities of participation in decision-making processes and in employment and productive opportunities are not threatened [4], they conclude that the challenges of eradicating poverty, inequality, the needs and demands of Care and the environmental crisis require overcoming the current sexual division of labor as a fundamental pillar to achieve equality in the 2030 agenda.

An interesting approach to finish understanding the phenomenon of care and its need is found in the historical journeys of the welfare regimes, since it allows us to analyze how it was considered a main responsibility of households (and within them, of women) and how the participation of the State was reserved for very specific aspects (for example, school education) or complementary aspects of the households when the particular situations warranted it (for example, in the case of households in situations of economic and social vulnerability). These approaches to well-being were questioned during the 1990s, as the women's and feminist movements promoted a vision of well-being focused on quality of life and not only on income and basic needs. These studies delved into the relationship between female headship and the well-being of families, considering income, poverty, predominance of informal and low-paid employment, hours dedicated to paid work, but also the characteristics of housing, child labor, school dropouts and domestic violence, and the findings showed the need to recognize the demographic and social heterogeneity of female-headed households and evaluate the relative contribution of each of the conditioning factors of household well-being. In short, they evidenced the need for non-traditional public policies, aimed at promoting gender equity and regulating a territory until recently considered the domain of private decisions, but despite its reflection in different types of social programs, it has not yet it has been installed in the dominant approach to well-being in the region.

If we inquire into care from the legal plane, we note that the Argentine Magistracy has long experience in pronouncements on medical-assistance care and personal care, obtaining favorable legal recognition supported by constitutional hierarchy norms that protect the protection of the right to life, health, physical integrity, among others Maza, et al. Exploring the most prominent decisions of our Courts are decisions that are still present in current jurisdictional responses where medical/assistance benefits are claimed [5]. We also found that the recognition of care work has been achieved by requesting financial compensation at the time of divorce [6]; when pricing the life of a person when they die or suffer an event that generates a disability in the workplace, or when a release or home arrest is requested, etc. [7].

\section{Where do we find its Theoretical Categorization or Normative Adaptation of Care?}

In recent years, care as a linguistic expression has had legal reception. We find that the new Civil and Commercial Code of the Nation incorporates it into the text to regulate the care of children and adolescents (hereinafter NNA) and people with restricted capacity, in Law 26,844 that regulates work at home individuals, as well as the Inter-American Convention on the Protection of the Human Rights of Older 
Persons. These norms begin to print broader notions to resignify situations that the law did not adopt, thus including the most basic aspects of daily life that make it sustainable and where the law could not be absent.

All these particularities, that is, the increase in demands for care from a social point of view and the increase in legal demands to obtain care, reflect the need to design public policies that address care in all its dimensions, to avoid an impairment of access to rights, and jeopardize the effectiveness of the legal-regulatory system in the face of the requirements of those who must meet the needs of habilitation, rehabilitation and personal care to achieve their social inclusion and of those who require support to sustain the care within the family and obtain sufficient autonomy to access the exercise of their rights.

According to data collected by ECLAC-CELADE, the group of people over 80 years of age showed growth rates significantly higher than any other age group during the past four decades, a phenomenon that will continue to expand more rapidly than in the rest of the country population, translating into an increase in health care costs, care demands and residential arrangements to provide assistance to this segment of the older population.

\section{Conclusion}

In this scenario, if the States do not provide public structures or support, it will be the family that is in charge of meeting the health and care needs required by the elderly, with disabilities or children, especially women (sisters, daughters, daughters-in-law and nieces) who have to respond individually to these demands, at the expense of their participation in the labor market or their personal fulfillment (CEPAL-CELADE). This phenomenon can become a dilemma if an equitable distribution system between genders and other actors that must intervene (State, society, unions) is not proposed to facilitate the equitable distribution of responsibilities and support, so that no one has to sacrifice the exercise of their rights in post of the exercise of the rights of others.

\section{References}

1. The GDP growth of Latin America and the Caribbean estimated in 2019 reaches $0.5 \%$, due to the greater complexities and risks presented by the international context, together with a fall in the dynamics of domestic aggregate demand, derived from the decrease in private consumption and the null contribution of investment and public spending to growth.

2. The unfair distribution of caregiving responsibilities is associated with the naturalization of women's ability to care; it was constructed as a social idea based on the biological characteristics of the sexes. This happens when it is considered that the exclusive biological capacity of women to give birth and breastfeed the endowments of supposed superior capacities for other aspects of care (such as sanitizing minors, preparing food, cleaning the house, organizing the various care activities necessary in a home), however, far from being a natural capacity, it is a social construction supported by subordination and discrimination on the basis of gender and cultural evaluations reproduced by various mechanisms such as education, the contents of advertisements and of other pieces of communication, tradition, daily domestic practices, religions and institutions, among others.

3. The Time Use Surveys allow counting unpaid work for the recognition of care as a right and the consequent implementation in the design of specific policies.

4. (2016) The Montevideo Strategy for the Implementation of the Regional Gender Agenda in the Framework of Sustainable Development by 2030 was approved at the XIII Regional Conference on Women in Latin America and the Caribbean organized by the Economic Commission for Latin America and the Caribbean (ECLAC) and the Government of Uruguay, held in Montevideo, pp: 19.

5. (2004) The Lifschitz case already cited is one of the most important cases that is present in every sentence regarding health care requirements for PCD. Other claims are linked to the Home Assistance provided for in art. 39, Law No. 24.901.

6. (2019) Civil Chamber. Room I. Case 4594/2016 (J. 92) “M. L., N. E. C. D. B., E.A. s/compensation setting”.

7. Art. 10 CPPN and art. 32 of the Law of execution of custodial sentence No. 23.660 (mod. By Law No. 26.472).

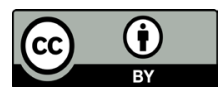

